\title{
TRABALHO DOCENTE COLETIVO NA EDUCAÇÃO FÍSICA ESCOLAR
}

\author{
Fabiano Bossle
}

Universidade Federal do Rio Grande do Sul, Porto Alegre, Rio Grande do Sul, Brasil

\section{Vicente Molina Neto}

Universidade Federal do Rio Grande do Sul, Porto Alegre, Rio Grande do Sul, Brasil

\section{Elisandro Schultz Wittizorecki}

Universidade Federal do Rio Grande do Sul, Porto Alegre, Rio Grande do Sul, Brasil

\section{Resumo}

Este artigo trata do trabalho coletivo dos professores de educação física de duas escolas do Município de Porto Alegre/RS. O problema de pesquisa formulado foi: Como os professores de educação física concebem e constroem o trabalho docente coletivo e quais os limites e possibilidades para essa construção no cotidiano de duas escolas desta Rede Municipal de Ensino? Realizamos uma etnografia em uma das escolas e uma autoetnografia em outra. Compreendemos que, independente das normativas da administração educativa, as condições para a construção de um trabalho coletivo, entre outras, estão relacionadas à configuração do contexto local de cada escola, das relações que a escola estabelece com estas comunidades e a vontade política das direções das escolas e dos coletivos docentes.

Palavras-chave: Docentes. Educação Física e Treinamento. Instituições Acadêmicas. Pesquisa Qualitativa.

\section{Introdução}

presente artigo trata do trabalho docente coletivo dos professo-
res de educação física da Rede de Ensino de Porto Alegre/RS a partir de uma investigação que aproximou as informações de uma etnografia e uma autoetnografia (BOSSLE, 2008). Nesta Rede de Ensino, assim como em outras tantas, o trabalho coletivo é pensado como a possibilidade de viabilizar o projeto político e pedagógico através do diálogo entre professores, equipes diretivas, supervisão pedagógica, funcionários, estudantes, pais e comunidade no entorno da escola e materializar procedimentos metodológicos que acolham à coletividade. Contudo, talvez as práticas educativas no contexto macro social e 
no interior das escolas ainda não estejam configuradas em uma perspectiva que privilegie a construção do trabalho docente coletivo.

O que nos propomos neste texto é compreender quais os limites e possibilidades da construção do trabalho docente coletivo dos professores de educação física de duas escolas da Rede de Ensino de Porto Alegre. O problema de pesquisa formulado ficou assim delimitado: Como os professores de Educação Física concebem e constroem o trabalho docente coletivo e quais são as possibilidades e os limites com relação a esta construção em duas Escolas Municipais de Porto Alegre? Dessa forma, para que o leitor tenha uma noção exata de como nos aproximamos do problema do estudo apresentaremos de modo breve as decisões teórico-metodológicas adotadas para compreender o trabalho docente coletivo.

\section{Caminhos metodológicos}

Optamos pela realização de uma etnografia em uma escola onde havia evidências de trabalho coletivo entre os professores de educação física e de uma autoetnografia em outra escola pública municipal de Porto Alegre, onde estas evidências não eram tão claras. A etnografia foi realizada na escola Ilha de utopia, nome baseado na obra "Utopia" de Thomas More e a autoetnografia foi realizada na escola Olho do furacão, denominação que remete ao momento complicado pela qual esta escola passava, localizando-se no centro de uma disputa pelo controle do tráfico de drogas em um bairro de Porto Alegre com índices elevados de violência.

O trabalho de campo teve início com o contato preliminar com o setor de Assessoria Pedagógica da Educação Física da Secretaria Municipal de Educação de Porto Alegre em outubro de 2006. Neste setor houve a indicação de uma escola na região sul de Porto Alegre onde o trabalho coletivo era um eixo norteador das práticas educativas na escola Ilha de Utopia. Ainda no mês de outubro de 2006, nos apresentamos à escola e obtivemos o consentimento para realizar a etnografia, que se estendeu até o mês de dezembro de 2007. Já, a autoentografia iniciou no mês de março de 2007 quando um de nós assumiu como professor concursado o regime de trabalho de 20 horas semanais e, em seguida, mais 10 horas semanais no turno da tarde na escola Olho do furacão e encerrou no mês de janeiro de 2008. 
Os instrumentos de coleta das informações utilizados na etnografia foram a observação participante, os diálogos, o diário de campo, as entrevistas com dois professores de educação física e com a diretora da escola e a análise de documentos da escola e dos professores. $\mathrm{Na}$ autoetnografia adotamos a condição de participantes observadores, já que ao mesmo tempo em que exercíamos a função de professores de educação física da escola, assumíamos o processo de investigação sobre o trabalho coletivo. Na autoetnografia adotamos ainda os diálogos e entrevistas gravadas e transcritas com os colegas de educação física (cinco) e mais duas participantes privilegiadas (a diretora e a supervisora pedagógica), questionários, análises de nossos próprios documentos e da escola e, por último, o registro constante em diários de campo.

\section{Entre utopias e furacões}

As concepções e as perspectivas de construção do trabalho coletivo dos professores de educação física foram interpretadas sobre o entendimento de que as atuais contingências econômicas, políticas e sociais, ao configurar a sociedade contemporânea em termos de "modernidade líquida", entre outras ações, desenvolvem estratégias para desestruturar as ações coletivas (BAUMAN, 1990). Entendendo que estamos inseridos em um ambiente fluído, onde as estruturas e as relações constituídas na modernidade sólida não conseguem garantir segurança às pessoas, sobram as incertezas e os medos de estar sozinho por não acompanhar a velocidade das mudanças sociais e econômicas.

O impacto desta desestruturação provocada pela fluidez da modernidade líquida pode ser percebido também na escola, uma instituição pautada nas "certezas da modernidade em sua forma sólida" (BAUMAN, 2001) e nas práticas que são construídas em seu interior. Ao defender uma postura de resistência aos avanços da globalização e do neoliberalismo e seu impacto na educação, Arroyo (1996) advoga por uma intervenção coletiva nas velhas estruturas do sistema escolar, sugerindo que os ciclos de formação podem contribuir para que ocorra uma renovação a partir de práticas coletivas.

Ao mesmo tempo em que os ciclos de formação são apontados como possibilidade de renovação a partir de práticas coletivas, portanto, como resistência à desintegração do fazer coletivo, também têm pro- 
movido sentimentos de desencanto e desilusão no professorado (DIEHL, 2007). Entendemos a análise da autora e sublinhamos que um dos principais elementos para a configuração do trabalho coletivo nesta rede escolar é o ensino organizado por ciclos de formação e as demandas que envolvem esta prática no cotidiano dos professores de educação física, bem como, os efeitos na prática educativa e sentimentos dos professores.

A proposta de organização do ensino por ciclos de formação implantada na Rede Municipal de Ensino de Porto Alegre tem gerado inquietações em pesquisadores de diferentes áreas de conhecimentos. Um número significativo de pesquisas foi e está sendo realizada sobre a Proposta Político-Pedagógica implantada nesta Rede de Ensino ou sobre alguns de seus aspectos subjacentes. O trabalho coletivo é um destes aspectos e está nesta Proposta como um dos pressupostos da organização curricular desta Rede de Ensino e, de maneira consequente, das práticas educativas dos professores, uma vez que, para Secretaria Municipal de Educação de Porto Alegre (1999), o currículo é uma "caminhada construída coletivamente" (p. 6).

Esta relação entre a Proposta e o trabalho coletivo tem surgido em outras pesquisas no âmbito da educação física. Mesmo abordando diferentes temáticas na perspectiva da educação física e ciências do esporte e o ensino organizado por ciclos de formação, o trabalho coletivo tem emergido nas seguintes pesquisas realizadas com este coletivo docente desta Rede de Ensino: Wittizorecki (2001) que investigou o trabalho docente, Bossle (2003) que investigou o planejamento de ensino, Pereira (2004) que investigou a interdisciplinaridade, Günther (2006) que investigou a prática pedagógica, Silva (2007) que investigou o processo de identização docente e Diehl (2007) que investigou o impacto das mudanças sociais na prática pedagógica do professorado de Educação Física.

De modo geral, estes estudos têm apresentado as limitações que os professores participantes apontam sobre a realização de trabalho coletivo nas escolas. Podemos interpretar que o trabalho coletivo pensado como pressuposto da Proposta desta Rede de Ensino tem promovido inquietações significativas nos professores de educação física, emergindo nos significados que atribuem às suas práticas educativas mesmo quando o foco central é discutir o seu trabalho docente, a interdisciplinaridade, o planejamento de ensino, a prática pedagógica, a identização ou as mudanças sociais. 
A relação entre os significados de trabalho coletivo e a Proposta Político-Pedagógica da Rede Municipal de Ensino de Porto Alegre para os participantes do presente estudo pode ser compreendida na existência ou não de um projeto pedagógico em cada escola. Esta interpretação vai de encontro à análise de Tardif e Lessard (2005) quando sublinham que a existência de um projeto coletivo na escola favoreceria o trabalho coletivo. Cada uma das escolas onde o estudo foi realizado apresentou, na perspectiva dos significados atribuídos por seus professores, condições diversas para a concretização ou não do trabalho coletivo, porém a construção do projeto pedagógico somente ocorreu em uma delas. Esta questão parece central na discussão sobre trabalho coletivo, ter ou não um projeto pedagógico construído coletivamente e seu desdobramento na prática educativa dos professores, uma vez que, segundo Molina e Molina Neto (2004), uma limitação à Proposta Político-Pedagógica na Rede Municipal de Ensino de Porto Alegre pode ser o fato de os professores de educação física não se sentirem sujeitos dessa Proposta.

Para o participante Rodrigo, que participou da construção coletiva do projeto pedagógico da escola Ilha de Utopia, “(...) este processo foi fundamental para criar o sentimento de pertencimento ao grupo e à escola" (registro em diário de campo no dia dez de maio de 2007). De acordo com a Proposta desta Rede de Ensino, cada escola tem autonomia para a construção de seu projeto pedagógico, contanto que isto ocorra com a participação de representantes de diferentes segmentos da comunidade escolar (equipe diretiva, supervisão pedagógica, professores, funcionários, pais e estudantes) (SECRETARIA MUNICIPAL DE EDUCAÇÃO DE PORTO ALEGRE, 1999).

Pensamos que este sentimento de pertencimento ao grupo e à Ilha de Utopia referenciado por Rodrigo tenha relação com a própria história da escola e da comunidade no seu entorno. Bibiana e Ana, que não participaram do início da construção do projeto pedagógico da escola, mas aderiram a ele posteriormente, manifestam que o trabalho coletivo foi uma forma de aproximação a esta cultura escolar específica de reconhecimento e identificação com as lutas e conquistas da comunidade e da escola. $\mathrm{O}$ trabalho coletivo aproximou os professores que estavam há mais tempo nesta escola dos que chegaram depois e compartilhavam desta visão de construção coletiva. Muitas vezes, ocorreram rituais de pertencimento na escola, como por exemplo, um 
jantar coletivo no horário de reunião no turno da noite (registro em diário de campo no dia quatorze de maio de 2007).

Mas o pertencimento ao grupo e ao projeto de escola não se estabeleceu pela qualidade das relações pessoais, outro fator apontado por Tardif e Lessard (2005) como facilitador para a construção de trabalhos coletivos nas escolas, mas apesar delas. É possível pensar que, a partir das informações de Rodrigo, Ana e Bibiana, a promoção de boas relações estabelecidas entre os professores na escola não estão livres de críticas e de autocríticas, justamente porque estariam amparadas em uma perspectiva de aprendizagem para todos e no desejo de querer trabalhar coletivamente e assumir este desafio cotidianamente em cada prática educativa. Esta disponibilização pessoal para se comprometer com o projeto pedagógico que tem no trabalho coletivo sua principal marca, passa pela identificação de cada professor com esta perspectiva de prática educativa, onde cada professor precisa se identificar com uma visão de homem, de educação e de escola.

Ao interpretar o trabalho coletivo nesta perspectiva, podem emergir algumas questões: Como desenvolver um trabalho docente coletivo sem ter clareza de o quê, com quem e por que a escola, constituída pelos diferentes segmentos da comunidade escolar, constrói educação? Como são construídas as práticas educativas de cada um dos professores de educação física desta escola? É possível pensar a existência de um trabalho docente coletivo sem o referencial de um projeto pedagógico?

Essas questões não foram pensadas com o objetivo de construir uma resposta objetiva, do tipo causa e efeito, mas como forma de problematizar o trabalho docente coletivo na perspectiva apresentada. Resgatar a história recente da escola Olho do furacão, talvez possa auxiliar na compreensão deste processo, já que revela um tensionamento com a Secretaria Municipal de Educação quando houve posicionamento contrário por parte desta escola em relação à implantação dos ciclos de formação e das demais reestruturações curriculares. Assim, interpretamos que esta posição em relação à Proposta PolíticoPedagógica da Secretaria possa, em primeiro lugar, ter sido provocado pelo tensionamento no interior da escola seriada, desde o ano de sua inauguração em 1957. Em segundo lugar, pelo coletivo docente da escola ter criado uma noção equivocada de autonomia ao manifestar contrariedade às reestruturações, pode ter havido uma desarticulação 
em relação ao projeto maior desta Rede de Ensino e, de maneira conseqüente, à organização de um projeto de escola.

Contudo, de acordo com Gandin (2006), quem quer apenas manter a estrutura e a cultura escolar intacta não necessita de projeto pedagógico. Na escola Ilha de utopia a cultura do entorno da escola, de lutas e conquistas coletivas é tido como um fator de identificação para a construção de trabalho coletivo na escola. Então, que leituras estão sendo realizadas pela comunidade escolar da escola Olho do furacão em relação à cultura que é compartilhada desde o entorno até o interior da escola? Para o professor Maneco, a não existência de um trabalho coletivo na escola Olho do furacão é uma questão que remete refletir sobre como é pensada e construída a estrutura da escola.

Estrutura e cultura de cada escola parecem questões significativas para a compreensão das inovações propostas pela Proposta da Secretaria de Educação e da possibilidade de construção do trabalho docente coletivo. A estrutura das escolas poderia ser pensada a partir de suas tipologias e dos seus espaços físicos. A tipologia se refere ao conjunto de características padrão que fazem uma escola ser considerada pequena, média ou grande, considerando-se o número total de estudantes (SECRETARIA MUNICIPAL DE EDUCAÇÃO DE PORTO ALEGRE, 1999). Assim, a escola Ilha de utopia é considerada de pequeno porte, por ter em torno de trezentos estudantes. Já, a escola Olho do furacão é considerada de grande porte, por acomodar em torno de mil e trezentos estudantes (informação de reunião nesta escola no dia quinze de maio de 2007). De acordo com Tardif e Lessard (2005), o tamanho do estabelecimento é outro fator que favorece - ou não - o trabalho docente coletivo. $\mathrm{O}$ envolvimento dos professores com seus pares, com os estudantes e com a equipe diretiva, assim como a distribuição dos espaços físicos, pode favorecer ou limitar a construção de práticas coletivas.

Pensamos que outro aspecto estrutural significativo para a construção de práticas coletivas na escola seja a configuração do/com o entorno. Por configuração entendemos desde a organização social até a política que envolve a escola. No caso da escola Olho do furacão, Luzia e Ismália destacaram em suas entrevistas que a comunidade no entorno da escola já foi mais organizada em outros momentos, mas que atualmente não está em função das disputas de poder. Encontramos informações sobre este aspecto destacado pelas professoras de que houve uma Associação de Moradores da Rua que se localiza na parte 
de trás da escola. Essa rua é denominada de "buraco". Em determinado momento, a referida associação se organizou e conquistou nos anos 1990 algumas antigas reivindicações, como o Posto de Polícia, a Unidade de Saúde e o asfaltamento de muitas ruas, além da "reinauguração" da Escola, já que a mesma era antes de madeira e desde 1996 é composta de quatro blocos de alvenaria e uma quadra esportiva coberta. Entendemos este movimento da comunidade no sentido de requerer uma escola, mas não de saber o que é feito em termos de aprendizagem em seu interior.

$\mathrm{Na}$ escola Ilha de utopia a organização e mobilização dos moradores para obter conquistas se traduziram na constituição de uma identidade coletiva transportada para dentro da escola. A organização política construída coletivamente, em ambas as escolas, produziu resultados em plano material e simbólico. Materiais seriam as conquistas referentes ao próprio bairro, como: saneamento, luz elétrica, asfaltamento e organização física das escolas, entendidas pelos moradores como prioridade. Simbólico seria o resultado da organização coletiva que sustenta as reivindicações do plano material.

Convivendo na escola Olho do furacão diariamente no ano letivo de 2007, não percebemos nenhum movimento organizado dos moradores da comunidade com a escola. Não foi possível identificar, ao longo do estudo, se há um movimento organizado dos moradores do entorno da escola e nem se ainda há uma organização coletiva qualquer que seja representativa destes moradores e seus anseios. Porém, é possível identificar que não houve desdobramentos de uma possível relação entre as práticas de reivindicação coletivas que ocorreram anteriormente e as relações que são estabelecidas hoje, entre escola e comunidade escolar.

Tendo abordado a estrutura que favoreceria o trabalho coletivo desde o entorno até o interior de cada escola, parece pertinente discutir a relação entre a cultura - dentro e fora da escola - e o trabalho docente coletivo. Ao propor a discussão sobre a cultura que favorece a construção da Proposta da Secretaria Municipal de Educação, do projeto pedagógico de cada escola e do trabalho coletivo, retomo a partir das crenças, atitudes, normas e valores que são compartilhados pelos integrantes destes sistemas sociais - as duas escolas do estudo. Hargreaves (1996) sublinha que as reformas estruturais - como a Proposta da Rede de Ensino de Porto Alegre [grifo nosso] - parecem pequenas, ineficazes e transitórias, frente à determinação que a cultura 
vigente impõe. Neste sentido, do ponto de vista cultural, as práticas educativas atuais podem ser compreendidas a partir da determinação que sofrem pelas crenças profundas, práticas e relações de trabalho entre os professores e a comunidade escolar que constituem a cultura da escola e as tradições do sistema.

Se, por um lado, os professores da escola Ilha de utopia foram aderindo "espontaneamente" (PÉREZ GOMÉZ, 1998) à identidade coletiva que privilegiava o trabalho docente coletivo, por outro lado, mesmo que houvesse o desejo individual manifesto pelos professores da escola Olho do furacão, não havia identidade coletiva e, como desdobramento disto, não havia trabalho coletivo. Para uns, a identidade docente se construía pautada na "força" que a representação de identidade coletiva representava, para outros, a cultura escolar dominante representava-se de maneira arraigada e o cotidiano escolar complexo e dinâmico parecia inviabilizar a busca de uma identidade coletiva, porque estava, como afirmam Maneco, Pedro, Leonor e Flora, "cada um fazendo a sua parte" (informação das entrevistas).

De maneira significativa, os participantes deste estudo manifestaram a importância de uma gestão na escola - equipe diretiva e supervisão pedagógica - que facilita ou não o trabalho coletivo. Destacamos que este fator não consta nas bibliografias pesquisadas sobre trabalho coletivo, mas consideramos, a partir da interpretação das informações coletadas junto aos professores nas duas escolas, que é um aspecto relevante neste estudo. Entendemos que a eleição de diretores na Rede de Ensino de Porto Alegre ganha sentido quando se trata de eleger um gestor que compartilhe do projeto político-pedagógico da escola e não um gestor de uma unidade administrativa, sem qualquer identidade.

A gestão de uma equipe diretiva na escola Ilha de utopia foi fundamental para articular a cultura de organização coletiva da comunidade no entorno da escola com o início de construção de um projeto que tem como pressuposto o trabalho coletivo. Este grupo que assumiu a gestão da escola buscou na identificação com esta cultura "de fora" reconhecer possibilidades de referenciais teóricos que discutiam a perspectiva de inclusão e de trabalho coletivo, amparado na própria análise diagnóstica sobre o que a escola precisava naquele momento (RODRIGO, nome fictício atribuído a professor participante do estudo). Esta legitimação da gestão da equipe diretiva nesta escola pode 
ser observada em diferentes situações e momentos durante o ano letivo de 2007.

A postura adotada pela equipe diretiva da escola Ilha de utopia nestes diferentes momentos foi o de buscar a participação e a escuta de todos para decidir. Isto ocorreu concretamente quando o coletivo docente foi chamado para discutir e decidir sobre a paralisação diante da iminência de greve em um dado momento. Ficou decidido que o grupo acataria a decisão de greve, participaria das atividades promovidas para reivindicar melhores condições salariais e recuperaria as aulas que desestruturaram o calendário escolar, tendo no segmento dos pais o respaldo positivo de apoio nestas decisões coletivas. Já, a vivência do mesmo episódio da greve na escola Olho do Furacão enunciou, a partir da postura adotada pela equipe diretiva desta escola, as limitações para construção de diálogos e participação de todos nas decisões que poderiam ser coletivas, mas que ficaram a critério de cada professor em aderir ou não ao movimento de paralisação.

Um fator significativo para pensar o trabalho coletivo docente nas duas escolas pesquisadas pode ser a "via de mão dupla" entre a cultura do entorno e a cultura no interior da escola. Os professores participantes do estudo destacaram que as marcas significativas da cultura viva e dinâmica do lado de fora das escolas e que é transportada para o lado de dentro, tem influenciado a possibilidade de construção de uma identidade coletiva. Em ambas as escolas ocorrem traduções que tem origem do lado de fora e que são representadas do lado de dentro. É possível perceber, então, os reflexos de fora para dentro e de dentro para fora, quando a escola recebe a desorganização e a devolve para a comunidade sem buscar a construção de um diálogo que promova a construção de uma coletividade.

Ao buscar a compreensão do trabalho docente coletivo a partir da dinâmica destas relações entre escola e comunidade, cultura e estrutura, fora e dentro, pensamos que ele pode ser interpretado como qualquer prática social. Esse entendimento não significa reduzi-lo em suas potencialidades de descrição e interpretação, mas justamente em compreendê-lo como uma prática social relacionada ao espaço/tempo do contexto cultural que o produz e o condiciona e/ou legitima.

Desse modo, a compreensão das informações sobre as inovações contidas na Proposta Político-Pedagógica da Secretaria Municipal de Educação de Porto Alegre e as possibilidades do projeto pedagógico na escola Ilha de Utopia e na escola Olho do Furacão revelou que es- 
trutura e cultura são aspectos significativos para a discussão sobre o trabalho docente coletivo. Pensamos que a estrutura administrativa e pedagógica da Secretaria de Educação tem favorecido a construção de práticas coletivas. O trabalho docente coletivo na Rede de Ensino de Porto Alegre é favorecido por esta estrutura na medida em que foram contempladas em sua Proposta a gestão democrática e a participação de todos nas decisões. No âmbito mais específico da prática educativa construída nas escolas, é possível perceber também esse favorecimento através da criação dos conselhos escolares, da eleição de diretores, da própria Proposta desta Rede de Ensino, da autonomia das escolas em relação à construção de seus projetos pedagógicos e do espaço para as reuniões semanais.

\section{Considerações finais}

O trabalho docente coletivo tem emergido na literatura de maneira significativa a partir das décadas de 1980 e 1990 porque a participação tem surgido como uma possibilidade de mudar a configuração de um modelo de escola amparado nas práticas individualizadas. Essas práticas individualizadas e desconectadas de um todo têm produzido, há algum tempo, a frustração dos coletivos docentes com os seus meios e os resultados. Contudo, a prática da participação e do envolvimento coletivo dos docentes em uma única atividade, embora desejada por muitos, envolve desprendimentos a crenças e práticas educativas que não mudam, simplesmente, de uma hora para outra.

Talvez possamos pensar que a estrutura da Rede de Ensino de Porto Alegre, de sua Proposta Político-Pedagógica e de seus desdobramentos e a existência ou não de um projeto pedagógico da escola, estejam tão fortemente imbricadas com a cultura e as crenças docentes - individuais e coletivas - que o trabalho docente coletivo possa ir da utopia ao furacão de maneira veloz. $\mathrm{O}$ trabalho coletivo na condição de pressuposto de uma proposta inovadora pode estar encontrando resistências ou facilidades em ambientes mais ou menos férteis para sua construção. Interpretamos que os Professores participantes deste estudo atribuem aos ambientes onde estão inseridos - as escolas - a presença ou não de uma potencialidade para o desenvolvimento de atitudes que visem à coletividade.

Os professores parecem sentir ameaçada a sua prática educativa individualizada, porque não reconhecem a cultura corporal de movi- 
mento dos estudantes e se mantém centrados na decisão pessoal sobre o processo de ensino-aprendizagem. Enfatizamos que a ausência de um plano de ensino da disciplina, além de revelar a falta de diálogo sobre o que fazemos, onde fazemos, com quem e porque nas aulas de educação física, reforça a atitude de isolamento que a autonomia, interpretada como a possibilidade de desenvolver o que quiser, tem promovido. O diálogo, um aspecto facilitador fundamental para o início e continuidade do trabalho docente coletivo nas escolas, parece limitar o reconhecimento das vivências corporais e culturais dos estudantes, entre os professores e entre eles e os estudantes.

\title{
Teacher collective work on physical education of school
}

\begin{abstract}
This article deals with the collective work of physical education teachers from two schools in the city of Porto Alegre / RS. The research problem was formulated: As physical education teachers design and build the collective work of teachers and what the limits and possibilities for this in the daily construction of two schools of Municipal School? We conducted an ethnography in a school and a autoetnografia another. We understand that, regardless of the norms of educational administration, the conditions for the construction of a collective work, among others, are related to the configuration of the local context of each school, the school establishes relationships with these communities and the political will of the leaderships of schools teachers and collectives.
\end{abstract}

Keywords: Faculty. Physical Education and Training. Schools. Qualitative Research.

\section{Trabajo colectivo de los maestros en la educación fisica}

\section{Resumen}

Este artículo trata de un trabajo colectivo de profesores de educación física de dos escuelas en la ciudad de Porto Alegre / RS. El problema de investigación se formuló: Como profesores de educación física diseñar y construir el trabajo colectivo de los profesores y cuáles son los límites y las posibilidades de este en la construcción diaria de dos escuelas de la Escuela Municipal? Se realizó una etnografía en una escuela y un autoetnografia otro. Entendemos que, independientemente de las normas de la administración educativa, las condiciones para la construcción de una obra colectiva, entre otros, están relacionados con la configuración del contexto local de cada escuela, la escuela establece relaciones con estas comunidades y la voluntad política de las direcciones de las escuelas los maestros y colectivos.

Palabras clave: Docentes. Educación y Entrenamiento Fisico. Instituciones Académicas. Investigación Cualitativa. 


\section{Referências}

ARROYO, M. Qualidade na Educação. Cadernos Pedagógicos SMED, Porto Alegre, n.9, p. 64-73, dez. 1996

BAUMAN, Z. Thinking Sociologically. Oxford/Cambridge: Blackwell Publishers, 1990.

. Modernidade Líquida. Rio de Janeiro: Jorge Zahar, 2001.

BOSSLE, F. Planejamento de Ensino dos Professores de Educação Física do $2^{\circ}$ e $3^{\circ}$ Ciclos da Rede Municipal de Ensino de Porto Alegre: um estudo do tipo etnográfico em quatro escolas desta Rede de Ensino. 2003. 271 f. Dissertação (Mestrado em Ciências do Movimento Humano)-Escola de Educação Física, Universidade Federal do Rio Grande do Sul, 2003.

. O "Eu do Nós": o professor de educação física e a construção do trabalho coletivo na Rede Municipal de Ensino de Porto Alegre. 2008. 341 f. Tese (Doutorado em Ciências do Movimento Humano)-Escola de Educação Física, Universidade Federal do Rio Grande do Sul, 2008.

DIEHL, V. R. O. O Impacto das Mudanças Sociais na Ação Pedagógica dos Docentes de Educação Física da Rede Municipal de Porto Alegre: implantação e implementação do Projeto Escola Cidadã. 2007. 237 f. Dissertação (Mestrado em Ciências do Movimento Humano)-Escola de Educação Física, Universidade Federal do Rio Grande do Sul, 2007.

GANDIN, L. A. Projeto Político-Pedagógico: construção coletiva do rumo da escola. In: LUCE, M. B.; MEDEIROS, I. L. P. Gestão Escolar Democrática: concepções e vivências. Porto Alegre: UFRGS, 2006. p. 67-72

GÜNTHER, M. C. C. A Prática Pedagógica dos Professores de Educação Física e o Currículo Organizado por Ciclos: um estudo na Rede Municipal de Ensino de Porto Alegre. 2006. 204 f. Tese (Doutorado em Ciências do Movimento Humano)-Escola de Educação Física, Programa de Pós-Graduação em Ciências do Movimento Humano, Universidade Federal do Rio Grande do Sul, 2006. 
HARgReAVES, A. Profesorado, Cultura y Postmodernidad: cambian los tiempos cambia el profesorado. Madrid: Morata, 1996.

MOLINA NETO, V.; MOLINA, R. K. O Que os Professores de Educação Física têm a Dizer sobre os Ciclos de Formação. In: MOLL, J. Ciclos na Escola, Tempos na Vida: criando possibilidades. Porto Alegre: ARTMED, 2004. p. 235 - 247

MORE, T. Utopia. 2. ed. São Paulo: Martins Fontes, 1999.

PEREIRA, R. R. A Interdisciplinaridade na Ação Pedagógica do Professor de Educação Física da Rede Municipal de Ensino de Porto Alegre. 2004. 247 f. Dissertação (Mestrado em Ciências do Movimento Humano)-Escola de Educação Física, Programa de PósGraduação em Ciências do Movimento Humano, Universidade Federal do Rio Grande do Sul, 2004.

PÉREZ GÓMEZ, A. I. La Cultura Escolar en la Sociedad Neoliberal. Madrid: Morata, 1998.

SECRETARIA MUNICIPAL DE EDUCAÇÃO DE PORTO ALEGRE. Ciclos de Formação, Proposta Político-Pedagógica da Escola Cidadã. Cadernos Pedagógicos, Porto Alegre, n. 9, abr., 1999.

SILVA, L. O. Um Estudo de Caso com Mulheres Professoras sobre o Processo de Identização Docente em Educação Física na Rede Municipal de Ensino de Porto Alegre. 2007. 227 f. Dissertação (Mestrado em Ciências do Movimento Humano)-Escola de Educação Física, Universidade Federal do Rio Grande do Sul, 2007.

TARDIF, M. O.; LESSARD, C. O Trabalho Docente: elementos para uma teoria da docência como profissão de interações humanas. Petrópolis/RJ: Vozes, 2005.

WITTIZORECKI, E. S. O Trabalho Docente dos Professores de Educação Física na Rede Municipal de Ensino de Porto Alegre: um estudo nas escolas do Morro da Cruz. 2001. 153 f. Dissertação (Mestrado em Ciências do Movimento Humano)-Escola de Educação Física, Universidade Federal do Rio Grande do Sul, 2001. 
Recebido em: 17/01/2012

Revisado em: 16/05/2012

Aprovado em: 19/06/2012

\section{Endereço para correspondência}

fabiano.bossle@ufrgs.br

Fabiano Bossle

Universidade Federal do Rio Grande Sul, Escola de Educação Física

Rua Felizardo, 750

Jardim Botânico

90690-200 - Porto Alegre, RS - Brasil 